radial cut-down), which was significantly less than femoral DSA minor adverse events $(p=0.0001)$. Radial to femoral conversion rate was $1.2 \%(7 / 607,2$ radial spasm, 2 unsuccessful radial artery access, 3 aberrant right subclavian artery). Femoral to radial conversion rate was 0.3\% (2/635). From March 2019 to February 2020, the proportion of DSA performed via transradial access increased from $36 \%$ to $78 \%$ at our institution.

Conclusion This study demonstrates the learning curves for both TRA and TFA diagnostic cerebral angiograms. Proficiency improves significantly with either type of access, typically requiring between 25-50 procedures. TRA DSA have significantly less access site complications than TFA DSA.

Disclosures M. Tso: None. G. Rajah: None. R. Dossani: None. M. Meyer: None. M. McPheeters: None. K. Vakharia: None. M. Waqas: None. K. Snyder: None. E. Levy: None. A. Siddiqui: None. J. Davies: None.

\section{E-106 EFFICACY OF ASAHI FUBUKI AS A GUIDING CATHETER FOR MECHANICAL THROMBECTOMY: AN INSTITUTIONAL CASE SERIES}

${ }^{1} \mathrm{~L}$ Rinaldo*, ${ }^{2} \mathrm{H}$ Cloft, ${ }^{3} \mathrm{~W}$ Brinjikji. ${ }^{1}$ Neurosurgery, Mayo Clinic, Rochester, MN; ${ }^{2}$ Radiology, Mayo Clinic, Rochester, MN; ${ }^{3}$ Radiology and Neurosurgery, Mayo Clinic, Rochester, MN

\subsection{6/neurintsurg-2020-SNIS.139}

Background Delivery of a guiding catheter to a suitable position is a critical step in performing mechanical thrombectomy (MT) for treatment of acute stroke secondary to large vessel occlusion. Over the past several years, we have employed the Asahi Fubuki (Asahi Intecc Co., LTD, 1976) as a first-line guide catheter for the performance of MT. Herein, we reviewed the treatment outcomes of MT cases in which the Fubuki was utilized to assess the efficacy of this catheter.

Methods Radiology reports of MT for the treatment of acute stroke secondary to large vessel occlusion during which the Fubuki was employed as a guide catheter were retrospectively reviewed. Information on patient characteristics and treatment outcomes was collected. Predictors of failure to deliver the Fubuki to the cervical internal carotid artery (ICA) were identified using logistic regression analysis.

Results There were 124 patients who met the inclusion criteria for analysis. Mean patient age was 77.8 years and a slight majority of patients were female (50.8\%). Large vessel occlusion occurred most often at the M1 segment $(41.1 \%)$ and most occlusions occurred on the patient's right side $(57.5 \%)$. The Fubuki was successfully delivered to the cervical ICA in 121 cases (97.6\%), and the lesion was successfully crossed with the Fubuki as the guide catheter in 119 cases (96.0\%). Herniation of the Fubuki into the aortic arch after delivery to the cervical ICA and cross-over to another guide catheter each occurred once $(0.8 \%)$ in separate cases. Greater than or equal to TICI $2 \mathrm{~B}$ revascularization was achieved in 100 patients $(80.6 \%)$. Median times to lesion crossed and revascularization were 9 and 19 minutes.

Conclusion Our results indicate that the Asahi Fubuki is an effective guide catheter for the performance of MT.

Disclosures L. Rinaldo: None. H. Cloft: None. W. Brinjikji: None.

\section{E-107 PREDICTORS OF DECOMPRESSIVE HEMICRANIECTOMY IN SUCCESSFULLY RECANALIZED PATIENTS WITH ANTERIOR CIRCULATION EMERGENCY LARGE VESSEL OCCLUSION}

${ }^{1} \mathrm{~N}$ Goyal ${ }^{*},{ }^{2} \mathrm{G}$ Tsivgoulis, ${ }^{2} \mathrm{~A}$ Pandhi, ${ }^{2} \mathrm{M}$ Ishfaq, ${ }^{2} \mathrm{~J}$ Goyanes, ${ }^{2} \mathrm{~A}$ Deep, ${ }^{2} \mathrm{D}$ Alsbrook, ${ }^{2} \mathrm{~S}$ Singh, ${ }^{2} \mathrm{G}$ Zaid, ${ }^{3} \mathrm{D}$ Hoit, ${ }^{3} \mathrm{C}$ Nickele, ${ }^{2} \mathrm{~V}$ Inoa, ${ }^{3} \mathrm{D}$ Dornbos, ${ }^{2} \mathrm{~A}$ Alexandrov, ${ }^{3} \mathrm{~A}$ Arthur, ${ }^{1} \mathrm{~L}$ Elijovich. ${ }^{1}$ Neurology and Neurosurgery, UTHSC, Memphis, TN; ${ }^{2}$ Neurology, UTHSC, Memphis, TN; ${ }^{3}$ Neurosurgery, UTHSC, Memphis, TN

\subsection{6/neurintsurg-2020-SNIS.140}

Background and Purpose Mechanical thrombectomy (MT) is demonstrated to improve functional outcome of patients with anterior circulation strokes with emergency large vessel occlusion (ELVO). Despite successful recanalization (SR), a proportion of these patients require decompressive hemicraniectomy (DHC). We aimed to study the predictors of DHC in successfully recanalized anterior circulation ELVO patients.

Methods Consecutive anterior circulation ELVO patients treated with MT during a 6-year period in a tertiary stroke center were evaluated. Only patients with SR (mTICI 2b, 2c or 3) after MT were included in the analysis. Baseline demographic, clinical and procedural variables were compared between the patients who required DHC after successful recanalization vs. who did not. Collaterals for anterior circulation ELVO (ie, poor (collateral score=0) vs. good (collateral score $=1,2$ and 3) were reported using a methodology that has been shown to predict clinical outcome. Good functional outcome was defined as mRS score of $0-2$ at 3 months. Univariable and multivariable logistic regression analyses were used to determine the predictors of DHC.

Results Of 453 successfully recanalized anterior circulation

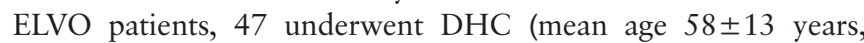
53\% male, median admission NIHSS-score: 17 points, IQR 13-21). The patients in DHC group were younger in age (mean age in years \pm SD; $58 \pm 13$ vs. $65 \pm 15, \mathrm{p}=0.004$ ), had higher admission systolic blood pressure (mmHg: $167 \pm 33$ vs. $155 \pm 30, \mathrm{p}=0.010)$, higher admission diastolic blood pressure (mmHg: $95 \pm 28$ vs. $87 \pm 19, \mathrm{p}=0.019$ ), higher admission blood glucose levels (mg/dl: $170 \pm 88$ vs. $142 \pm 66, \mathrm{p}=0.008$ ), similar median admission NIHSS (17 (IQR: 13-21) vs. 15 (IQR: 1120), $\mathrm{p}=0.087$ ), lower median ASPECTS (9 (IQR: 8-10) vs. 10 (IQR: 9-10), $\mathrm{p}=0.002)$, and poor collaterals on pre-treatment CT angiogram (\% with poor collaterals: $75 \%$ vs. $26 \%$, $\mathrm{p}<0.001)$ compared to those who did not required DHC. The DHC group required more passes during MT (median: 3 (IQR: 3-4) vs. 2 (IQR 1-2), p=0.001), had longer groin puncture to recanalization time (mean: $74 \pm 32$ vs. $55 \pm 35$, $\mathrm{p}<0.001$ ), while no difference was seen in symptoms onset to groin puncture time (mean: $313 \pm 166$ vs. $304 \pm 202, p=0.784$ ) compared to the non-DHC group. The patient in DHC group tended to have a higher $\mathrm{sICH}$ rate $(15 \%$ vs. $7 \%, \mathrm{p}=0.20)$, higher 3 months mortality $(41 \%$ vs. $16 \%, p=0.001)$ and lower rates of good functional outcome at 3 months $(26 \%$ vs. $58 \%, \mathrm{p}=0.001)$. In multivariable model after adjusting for various confounders, higher blood glucose levels on admission (OR per $1 \mathrm{mg} / \mathrm{dL}$ increase: 1.01; 95\% CI: 1.00-1.01, $\mathrm{p}=0.031$ ), poor collaterals on CT angiography (OR: 0.13 ; 95\% CI: $0.05-0.32, \mathrm{p}<0.001)$, and higher number of passes during MT (OR per 1 pass increase: 4.84; 95\% CI: 3.09$7.58, \mathrm{p}<0.001$ ) emerged as independent predictors of $\mathrm{DHC}$ in successfully recanalized ELVO patients.

Conclusion Higher blood glucose levels on admission, poor collateral pattern on CT angiography and higher number of 